\title{
Spectrum of corrosive esophageal injury after intentional paraquat or glyphosate-surfactant herbicide ingestion
}

This article was published in the following Dove Press journal:

International Journal of General Medicine

13 August 2013

Number of times this article has been viewed

\author{
Hsiao-Hui Chen' \\ Ja-Liang Lin' \\ Wen-Hung Huang' \\ Cheng-Hao Weng' \\ Shen-Yang Lee' \\ Ching-Wei Hsu' \\ Kuan-Hsing Chen' \\ I-Kuan Wang ${ }^{2}$ \\ Chih-Chia Liang ${ }^{2}$ \\ Chiz-Tzung Chang ${ }^{2}$ \\ Tzung-Hai Yen'
}

'Department of Nephrology and Division of Clinical Toxicology, Chang

Gung Memorial Hospital and Chang

Gung University, Taipei, Taiwan;

${ }^{2}$ Department of Nephrology, China

Medical University Hospital and China

Medical University, Taichung, Taiwan
Correspondence: Tzung-Hai Yen

Department of Nephrology, Chang Gung Memorial Hospital, 199 Tung Hwa North

Road, Taipei 105, Taiwan

Tel +886 $3328 \quad 1200$ ext 818।

Fax +8863328 2173

Emailm19570@adm.cgmh.org.tw
Background: Data on the spectrum of corrosive injury to the esophagus after paraquat or glyphosate-surfactant ingestion are sparse in the literature and confined to case studies and brief reports. Therefore, this study aimed to examine the clinical features, degrees of esophageal injury, and clinical outcomes after paraquat or glyphosate herbicide ingestion, and sought to determine what association, if any, may exist between these findings.

Methods: We performed an observational study on 47 patients with paraquat or glyphosate ingestion who underwent endoscopic evaluation over a period of 11 years (2000-2011).

Results: Corrosive esophageal injuries were classified as grade 1 in 14 (glyphosate-surfactant) and three (paraquat), grade $2 \mathrm{a}$ in nine (glyphosate-surfactant) and 18 (paraquat), and grade $2 \mathrm{~b}$ in one (glyphosate-surfactant) and two (paraquat) patients. No patients had grade $0,3 \mathrm{a}$, or $3 \mathrm{~b}$ esophageal injuries. Therefore, the severity of corrosive injury was more severe in the paraquat group $(P=0.005)$. After toxin ingestion, systemic toxicity occurred, with rapid development of systemic complications in many cases. Neurologic complications occurred more frequently in the glyphosate-surfactant group $(29.2 \%$ versus $0 \%, P=0.005)$, although respiratory failure ( $4.2 \%$ versus $34.8 \%, P=0.008)$, hepatitis $(12.5 \%$ versus $52.2 \%, P=0.004)$, and renal failure (20.8\% versus $52.2 \%, P=0.025)$ developed more frequently in the paraquat group. Patients with glyphosate poisoning had shorter hospital stays than patients with paraquat poisoning $(13.3 \pm 15.1$ days versus $26.8 \pm 10.2$ days, $P=0.001)$. Nevertheless, there was no significant difference in mortality rate between the glyphosate-surfactant and paraquat groups $(8.3 \%$ versus $13.0 \%, P=0.601)$. We ultimately found that patients with grade $2 \mathrm{~b}$ esophageal injury suffered from a greater incidence of respiratory $(100.0 \%$ versus $5.9 \%, P=0.001)$ and gastrointestinal (66.7\% versus $11.8 \%, P=0.034)$ complications than patients with grade 1 injury, regardless of herbicide type.

Conclusion: Paraquat and glyphosate are mild caustic agents that produce esophageal injuries of grades $1,2 \mathrm{a}$, and $2 \mathrm{~b}$ only. Our data also suggest a potential relationship between the degree of esophageal injury and systemic complications.

Keywords: paraquat, glyphosate-surfactant, poisoning, suicide, esophageal injury

\section{Introduction}

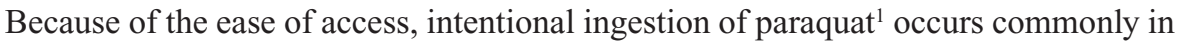
Taiwan. Paraquat is a widely used bipyridyl contact herbicide with a good safety record when used properly. However, the lethal toxicity of this compound always results in a high mortality rate. There are three degrees of severity for paraquat poisoning following ingestion. ${ }^{2}$ Mild poisoning initially induces oral irritation and gastrointestinal upset but eventually results in a complete recovery. Moderate to severe poisoning typically results in acute renal failure, whereas in severe cases, acute hepatitis is followed by 
either pneumonitis or pulmonary fibrosis, which often results in death after 2-3 weeks. Finally, acute fulminant poisoning results in death within a week due to multiple organ failure and cardiovascular collapse. ${ }^{2}$ Many treatment modalities have been developed for paraquat poisoning, including adsorbents, hypo-oxygenation, lung radiotherapy, ${ }^{3}$ prolonged extracorporeal detoxification, ${ }^{4}$ and lung transplantation. However, the efficacies of these therapeutic methods remain uncertain.

At our hospital, all patients with paraquat poisoning are treated using a standard detoxification protocol. ${ }^{1,5-10}$ This protocol consists of repeated pulses of methylprednisolone and cyclophosphamide followed by prolonged dexamethasone therapy. Using this practice, the respiratory function and blood oxygen concentrations in most patients returned to near-normal levels in 3-6 months. ${ }^{11}$ Notably, there is no specific antidote for paraquat intoxication. ${ }^{12}$

Glyphosate-surfactant is a broad spectrum, nonselective herbicide that is extensively used in agriculture in Taiwan. The glyphosate-surfactant herbicides available on the agrochemical market in Taiwan are formulated commercial products that contain isopropylamine salt of glyphosate, variable amounts of surfactant, and water. ${ }^{13}$ The ingestion of glyphosate-surfactant is reported to cause significant toxicity, including oral irritation, gastrointestinal upset, renal and hepatic impairment, respiratory distress, pulmonary edema, shock, and disturbance of consciousness. ${ }^{14}$ The mechanism of toxicity of glyphosate-surfactant formulations in humans is unclear, ${ }^{14}$ because both the herbicide and surfactant may contribute to toxicity. It is also unknown whether mixing glyphosate with a surfactant could enhance the toxicity. Nevertheless, there is no available antidote for glyphosatesurfactant poisoning, and its management is principally symptomatic and supportive. ${ }^{14}$

Data on the spectrum of corrosive injury to the esophagus after paraquat ${ }^{6,15-19}$ or glyphosate-surfactant ${ }^{20-24}$ ingestion are sparse in the literature and confined to case studies and brief reports. There have been occasional reports of severe damage to the esophagus; however, the location, extent, and severity of the damage have not been clearly defined. The use of paraquat has been questioned and discussed for decades by international and national regulatory bodies as well as nongovernmental organizations, and many countries have banned its use; ${ }^{25}$ as a result, few related studies have been published. Therefore, this observational study examined the clinical features, degrees of esophageal injury, and clinical outcomes after paraquat or glyphosate-surfactant ingestion, and sought to determine what association, if any, may exist between these findings.

\section{Materials and methods}

\section{Ethics statement}

This retrospective observational study complied with the guidelines of the Declaration of Helsinki and was approved by the medical ethics committee of Chang Gung Memorial Hospital. Because of the retrospective nature of this study, institutional review board approval (99-1073B) was obtained and the informed consent of the risk of endoscopic examinations and treatment modalities provided by all patients on their initial admission was used. Moreover, all individual information was securely protected (by delinking identifying information from the main dataset) and made available only to the investigators. All of the data were analyzed anonymously, and all primary data were collected according to the Strengthening the Reporting of Observational Studies in Epidemiology guideline. This policy was based on a previous publication. ${ }^{26}$

\section{Patients}

Here we performed a retrospective observational study on all patients with paraquat or glyphosate-surfactant poisoning admitted to the Chang Gung Memorial Hospital over a period of 11 years (2000-2011). Only patients with paraquat and glyphosate ingestions for whom endoscopic evaluations were performed were included in the study.

\section{Diagnosis of paraquat or glyphosate- surfactant poisoning}

A presumptive diagnosis of paraquat poisoning was based on exposure history, clinical effects, and physical and laboratory examinations (especially urine sodium dithionite screening test). ${ }^{1,5-10}$ The urine sodium dithionite reaction was dependent on reduction of paraquat by sodium thionite under alkaline conditions to form stable blue-colored radical ions. The generation of a strong navy or dark blue color generally indicates significant paraquat ingestion and often indicates a poor prognosis. Nevertheless, the urine test was used as a paraquat screen, and a confirmatory diagnosis of paraquat poisoning was only possible by checking blood paraquat levels using a spectrophotometer (Hitachi, Tokyo, Japan). Similarly, the diagnosis of glyphosate-surfactant poisoning was based on exposure history, clinical effects, and physical and laboratory examinations. ${ }^{14}$

\section{Inclusion and exclusion criteria}

All patients $>18$ years of age diagnosed with either paraquat or glyphosate-surfactant poisoning at Chang Gung Memorial Hospital between 2000 and 2011 were eligible 
for inclusion in this study. Patients with paraquat poisoning were excluded from this study if they were $<18$ years or if the paraquat exposure was dermal or intravascular. They were also excluded if they did not have detectable paraquat levels in their urine and blood (despite suspicion of exposure) or had major comorbidities such as cancer, heart, lung, renal, or liver disease. Similarly, patients with glyphosatesurfactant poisoning were excluded from this study if they were $<18$ years or if they had major comorbidities such as cancer, heart, lung, renal, or liver disease.

\section{Paraquat or glyphosate-surfactant detoxification protocol}

The protocol ${ }^{1,5-10}$ includes gastric lavage with a large amount of normal saline followed by active charcoal administration, charcoal hemoperfusion, and pulse therapies of cyclophosphamide and methylprednisolone followed by dexamethasone therapy as well as repeated glucocorticoid and cyclophosphamide pulse therapies in cases of hypoxemia. Similarly, glyphosate-surfactant patients were intensively treated by gastric lavage with a large amount of normal saline followed by active charcoal administration. As mentioned, there is no antidote available for glyphosate-surfactant poisoning, and its management is mainly symptomatic and supportive. ${ }^{14}$

\section{Endoscopic examination and grading}

After an overnight fast, upper gastrointestinal endoscopy was performed using a standard flexible endoscope. Injury to the upper gastrointestinal tract was reported as described by Zargar et al: grade 0, normal findings; grade 1, edema, hyperemia of mucosa; grade $2 \mathrm{a}$, friability, blisters, hemorrhaging, erosions, whitish membranes, exudates, and superficial ulcerations; grade $2 \mathrm{~b}$, grade $2 \mathrm{a}$ plus deep discrete or circumferential ulcerations; grade 3a, small scattered areas of multiple ulcerations and areas of necrosis (brown-black or grayish discoloration); and grade $3 \mathrm{~b}$, extensive necrosis. ${ }^{27}$

\section{Definitions of clinical events}

Neurologic complications were defined if a patient experienced a seizure with a disturbance of consciousness. Cardiovascular complications were defined as patients suffering from hypotension, shock, or arrhythmia. Respiratory failure was defined as intubation. Gastrointestinal bleeding episodes were recorded as hematemesis, melena, or hematochezia. Acute renal failure was documented if serum creatinine increased to $>1.4 \mathrm{mg} / \mathrm{dL}$ (normal 0.4-1.4 mg/dL). Acute hepatitis was documented when serum alanine aminotransferase was $>70 \mathrm{U} / \mathrm{L}$ (normal 0-36 U/L) or when total bilirubin was $>3.0 \mathrm{mg} / \mathrm{dL}$ (normal $0-1.3 \mathrm{mg} / \mathrm{dL})$.

\section{Statistical analysis}

Data are expressed as the mean \pm standard deviation or number and percentage in parentheses unless otherwise stated. All analyses were performed using IBM Statistical Package for the Social Sciences version 20 software (IBM, Armonk, NY, USA). Data were routinely tested for normality of distribution and equality of standard deviations before the analysis. For comparisons between patient groups, the Student's $t$-test was used for quantitative variables, whereas the Chi-square or Fisher's Exact test was used for categorical variables. The criterion for significance was the $95 \%$ confidence interval to reject the null hypothesis.

\section{Results}

Table 1 outlines the patient characteristics at baseline. We found that patients with glyphosate-surfactant poisoning were older $(56.8 \pm 17.6$ years versus $36.4 \pm 13.8$ years, $P<0.001)$ but received endoscopic examinations sooner ( $4.4 \pm 6.9$ days versus $9.3 \pm 6.4$ days, $P=0.016$ ) than patients with paraquat poisoning. Otherwise, there were no significant differences in other baseline variables between the two groups.

As shown in Table 2, corrosive esophageal injuries were classified as grade 1 in 14 (glyphosate-surfactant) and three (paraquat) patients, grade $2 \mathrm{a}$ in nine (glyphosate-surfactant) and 18 (paraquat) patients, and grade $2 \mathrm{~b}$ in one (glyphosatesurfactant) and two (paraquat) patients. No patients had grade $0,3 \mathrm{a}$, or $3 \mathrm{~b}$ esophageal injuries. The severity of corrosive injury was greater in the paraquat group than in the glyphosate-surfactant group $(P=0.005)$.

After toxin ingestion, systemic toxicity occurred with the rapid development of systemic complications in many cases (Table 3). Neurologic complications occurred more frequently in the glyphosate-surfactant group $(29.2 \%$ versus $0 \%$, $P=0.005)$, although respiratory failure (4.2\% versus $34.8 \%$, $P=0.008)$, hepatitis (12.5\% versus $52.2 \%, P=0.004)$, and renal failure $(20.8 \%$ versus $52.2 \%, P=0.025)$ developed more frequently in the paraquat group.

Patients with paraquat poisoning were intensively treated using a standard detoxification protocol (Table 4). In contrast, patients with glyphosate-surfactant poisoning received the best supportive medical care. Patients with glyphosate poisoning stayed in hospital for a shorter duration than patients with paraquat poisoning (13.3 \pm 15.1 days versus $26.8 \pm 10.2$ days, $P=0.001)$. Nevertheless, there 
Table I Baseline characteristics of patients with paraquat or glyphosate-surfactant poisoning who underwent endoscopic evaluation $(n=47)$

\begin{tabular}{|c|c|c|c|c|}
\hline Variable & Glyphosate-surfactant $(n=24)$ & Paraquat $(n=23)$ & Chi-square & $P$-value \\
\hline Male, n (\%) & $16(66.7)$ & $13(56.5)$ & 0.512 & 0.474 \\
\hline Age, years & $56.8 \pm 17.6$ & $36.4 \pm 13.8$ & & $<0.001 * * *$ \\
\hline Intentional, n (\%) & $20(83.3)$ & I8 (78.3) & 0.195 & 0.659 \\
\hline Diabetes mellitus, $\mathrm{n}(\%)$ & $3(12.5)$ & $0(0)$ & $3.07 \mid$ & 0.080 \\
\hline Hypertension, n (\%) & I (4.2) & $0(0)$ & 0.979 & 0.322 \\
\hline Serum paraquat level, $\mu \mathrm{g} / \mathrm{mL}$ & & $1.3 \pm 2.2$ & & \\
\hline $\begin{array}{l}\text { Interval from poisoning } \\
\text { to detoxification treatment, days }\end{array}$ & $0.2 \pm 0.4$ & $0.6 \pm 0.8$ & & 0.057 \\
\hline $\begin{array}{l}\text { Interval from poisoning } \\
\text { to endoscopy, days }\end{array}$ & $4.4 \pm 6.9$ & $9.3 \pm 6.4$ & & $0.016 * *$ \\
\hline $\begin{array}{l}\text { White blood } \\
\text { cell count } / \mathrm{mm}^{3}\end{array}$ & $12,258 \pm 5,102$ & $10,426 \pm 4,148$ & & 0.185 \\
\hline
\end{tabular}

Notes: $* * P<0.01 ; * * * P<0.001$.

was no significant difference in mortality rates between the glyphosate-surfactant and paraquat groups $(8.3 \%$ versus $13.0 \%, P=0.601)$.

Our findings suggested that the magnitude of corrosive esophageal injury (a local complication) might be associated with systemic complications regardless of herbicide type (Table 5). For example, patients with grade 2 b esophageal injuries suffered from greater incidences of respiratory failure $(100.0 \%$ versus $5.9 \%, P=0.001)$ and gastrointestinal bleeding $(66.7 \%$ versus $11.8 \%, P=0.034)$ than patients with grade 1 injuries.

\section{Discussion}

As mentioned, data on the spectrum of corrosive injury to the esophagus after paraquat ingestion are sparse in the literature and confined to case studies and brief reports. ${ }^{6,15-19}$ In 1978, Ackrill et al ${ }^{15}$ reported two fatal cases of esophageal perforation due to paraquat ingestion. The striking feature noted in these two cases was total ulceration of the esophageal mucosa, but the stomach was spared. Whether the lack

Table 2 Spectrum of corrosive esophageal injury (local complication) after paraquat or glyphosate-surfactant ingestion $(n=47)$

\begin{tabular}{lllll}
\hline $\begin{array}{l}\text { Corrosive } \\
\text { esophageal } \\
\text { injury }\end{array}$ & $\begin{array}{l}\text { Glyphosate- } \\
\text { surfactant } \\
(\mathbf{n}=\mathbf{2 4})\end{array}$ & $\begin{array}{l}\text { Paraquat } \\
(\mathbf{n}=\mathbf{2 3})\end{array}$ & Chi-square & P-value \\
\hline $\begin{array}{l}\text { Grade, } \mathrm{n}(\%) \\
0\end{array}$ & $0(0)$ & $0(0)$ & 10.434 & $0.005^{* *}$ \\
I & $14(58.3)$ & $3(13.0)$ & & \\
$2 \mathrm{a}$ & $9(37.5)$ & $18(78.3)$ & & \\
$2 \mathrm{~b}$ & $\mathrm{I}(4.2)$ & $2(8.7)$ & & \\
$3 \mathrm{a}$ & $0(0)$ & $0(0)$ & & \\
$3 \mathrm{~b}$ & $0(0)$ & $0(0)$ & & \\
\hline
\end{tabular}

Note: $* * p<0.01$. of gastric ulceration was due to the type of epithelium, the presence of acid or mucus, or other local factors is unknown. Mui and Epp ${ }^{19}$ did a retrospective study of 38 paraquatinduced upper gastrointestinal tract injury cases during the period of 1986-1989. Fifty-three sessions of endoscopy were performed. The endoscopic assessments of buccal, esophageal, and gastric lesions were classified into grades I, II, III, and IV according to injury severity. A total of five, six, ten, and 17 patients, respectively, were classified in these four different groups. Grade I lesions were lesions confined to the oral or pharyngeal mucosa only. Grade II lesions were lesions in the oral cavity combined with focal esophageal lesions. Grade III lesions were defined as any form of oral and diffuse esophageal lesions but without gastric lesions. Grade IV lesions consisted of any combination of oral and esophageal lesions accompanied by gastric lesions. Patients with grade III or IV injury had a worse

Table 3 Systemic complications after paraquat or glyphosatesurfactant ingestion $(n=47)$

\begin{tabular}{lllll}
\hline Variable & $\begin{array}{l}\text { Glyphosate- } \\
\text { surfactant } \\
(\mathbf{n}=\mathbf{2 4})\end{array}$ & $\begin{array}{l}\text { Paraquat } \\
(\mathbf{n}=\mathbf{2 3})\end{array}$ & $\begin{array}{l}\text { Chi- } \\
\text { square }\end{array}$ & P-value \\
\hline $\begin{array}{l}\text { Neurologic } \\
\text { complications, n (\%) }\end{array}$ & $7(29.2)$ & $0(0)$ & 7.882 & $0.005^{* *}$ \\
$\begin{array}{l}\text { Cardiovascular } \\
\text { complications, n (\%) }\end{array}$ & $3(12.5)$ & $\mathrm{I}(4.3 \%)$ & 1.002 & 0.317 \\
$\begin{array}{l}\text { Acute respiratory } \\
\text { failure, } \mathrm{n}(\%)\end{array}$ & $\mathrm{I}(4.2)$ & $8(34.8)$ & $7.11 \mathrm{I}$ & $0.008^{* *}$ \\
$\begin{array}{l}\text { Gastrointestinal } \\
\text { bleeding, } \mathrm{n}(\%)\end{array}$ & $4(16.7)$ & $3(13.0)$ & 0.122 & 0.727 \\
$\begin{array}{l}\text { Acute hepatitis, } \\
\mathrm{n}(\%)\end{array}$ & $3(12.5)$ & $12(52.2)$ & 8.508 & $0.004 * *$ \\
$\begin{array}{l}\text { Acute renal failure, } \\
\mathrm{n}(\%)\end{array}$ & $5(20.8)$ & $12(52.2)$ & 4.997 & $0.025 *$ \\
\hline Notes: $* \mathrm{P}<0.05 ; * * \mathrm{P}<0.01$. & & & \\
\hline
\end{tabular}


Table 4 Treatments and outcomes after paraquat or glyphosate-surfactant ingestion $(n=47)$

\begin{tabular}{|c|c|c|c|c|}
\hline Variable & Glyphosate-surfactant $(n=24)$ & Paraquat $(n=23)$ & Chi-square & $P$-value \\
\hline Gastric lavage, n (\%) & $6(25.0)$ & $14(60.9)$ & 6.182 & $0.013^{*}$ \\
\hline Activated charcoal and magnesium citrate, $\mathrm{n}(\%)$ & $10(41.7)$ & $9(39.1)$ & 0.031 & 0.859 \\
\hline $\begin{array}{l}\text { Glucocorticoid and cyclophosphamide } \\
\text { pulse therapy, } n(\%)\end{array}$ & $0(0)$ & $23(100.0)$ & 47.000 & $<0.001 * * *$ \\
\hline Charcoal hemoperfusion, n (\%) & $0(0)$ & $19(82.6)$ & 33.280 & $<0.00 I^{* * *}$ \\
\hline Length of hospital stay, days & $13.3 \pm 15.1$ & $26.8 \pm 10.2$ & & $0.001 * *$ \\
\hline Mortality, n (\%) & $2(8.3)$ & $3(13.0)$ & 0.274 & 0.601 \\
\hline
\end{tabular}

Notes: $* p<0.05 ; * * p<0.01 ; * * * p<0.001$.

prognosis than those with grade I or II injury. The authors also found that buccal mucosal erosion, ulceration, hemorrhage, and pseudomembranous formation were identified in the esophagus and stomach as the injury process progressed. Gastric erosion was an ominous endoscopic sign related to a high mortality rate. ${ }^{19}$ Valiante et al ${ }^{16}$ later described a victim of severe panesophagitis and localized erosive hemorrhagic gastritis after accidental oral diquat exposure during work. Subsequently, Tanen et al ${ }^{17}$ also reported a case of esophagitis after the ingestion of a diluted diquat solution. Furthermore, Singh et al ${ }^{18}$ presented two lethal cases of caustic esophageal burning after paraquat ingestion.

In our preliminary study, ${ }^{6} 16$ of 1,410 paraquat subjects who underwent endoscopies at Chang Gung Memorial Hospital between 1980 and 2007 were retrospectively analyzed. Corrosive esophageal injuries were classified as grade 1 in eight patients, $2 \mathrm{a}$ in five patients, and $2 \mathrm{~b}$ in three patients. No patients had grade $0,3 \mathrm{a}$, or $3 \mathrm{~b}$ esophageal injuries. After paraquat ingestion, systemic toxicity occurred with rapid development of hypoxia, hepatitis, and renal failure in many cases. Hypoxia occurred in one (12.5\%), five (100\%), and three $(100 \%)$ patients with grades $1,2 \mathrm{a}$, and $2 \mathrm{~b}$ esophageal injury, respectively. More patients with hypoxia had grades $2 \mathrm{a}$ and $2 \mathrm{~b}$ than grade 1 esophageal injury $(P<0.05)$. The nadir partial pressure of oxygen in the arterial blood was lower in patients with grades $2 \mathrm{a}$ and $2 \mathrm{~b}$ than in those with grade 1 esophageal injury $(P<0.05)$. Therefore, it was concluded that paraquat was a mild caustic agent because it produced only grades $1,2 \mathrm{a}$, and $2 \mathrm{~b}$ esophageal injury after ingestion. ${ }^{6}$ The findings also showed a potential relationship between degree of hypoxia, mortality, and degree of esophageal injury. ${ }^{6}$

Similarly, there are only a few reports ${ }^{20-24}$ in the literature regarding the corrosive outcomes of glyphosate-surfactant ingestion. In 1991, Talbot et $\mathrm{al}^{21}$ reported that ingestion of glyphosate-surfactant caused gastrointestinal erosion and hemorrhage in $66 \%$ and $8 \%$ of patients, respectively. Moreover, Tominack et $\mathrm{a}^{22}$ reported that irritation of the oral mucosa and gastrointestinal tract was the most frequent effect after glyphosate-surfactant ingestion. Another study ${ }^{20}$ revealed that corrosive esophageal injury was present in $68 \%$, gastric injury in $72 \%$, and duodenal injury in $16 \%$ of patients. There were no grade 3 injuries after glyphosate-surfactant ingestion. There were recent case reports of extensive burns and ulceration of the oral cavity after accidental exposure ${ }^{24}$ as well as gastric mucosa hemorrhage and small intestine dilatation after deliberate ingestion. ${ }^{23}$

Neurologic complications occurred more frequently in the glyphosate-surfactant group than in the paraquat group (29.2\% versus $0 \%, P=0.005)$. Studies have shown that after glyphosate ingestion, consciousness disturbances of $12 \%-32.9 \%$ occur. ${ }^{21,28}$ The mechanisms involved in paraquatinduced or glyphosate-surfactant-induced brain damage are unclear. Experimental research demonstrated a role of

Table 5 Association between local and systemic complications after paraquat or glyphosate-surfactant ingestion $(n=47)$

\begin{tabular}{|c|c|c|c|c|c|}
\hline \multirow[t]{2}{*}{ Variable } & \multicolumn{5}{|c|}{ Corrosive esophageal injury } \\
\hline & Grade I $(n=17)$ & Grade $2 a(n=27)$ & Grade $2 b(n=3)$ & Chi-square & $P$-value \\
\hline Neurologic complications, n (\%) & $2(11.8)$ & $4(14.8)$ & I (33.3) & 0.936 & 0.626 \\
\hline Cardiovascular complications, n (\%) & $\mathrm{I}(5.9)$ & $2(7.4)$ & I (33.3) & 2.567 & 0.277 \\
\hline Acute respiratory failure, $\mathrm{n}(\%)$ & I (5.9) & $5(18.5)$ & $3(100.0)$ & 14.606 & $0.00 I^{* *}$ \\
\hline Gastrointestinal bleeding, n (\%) & $2(11.8)$ & $3(I I . I)$ & $2(66.7)$ & 4.590 & $0.034 *$ \\
\hline Acute hepatitis, n (\%) & $3(17.6)$ & II (40.7) & I (33.3) & 2.563 & 0.278 \\
\hline Acute renal failure, $\mathrm{n}(\%)$ & $3(17.6)$ & $12(44.4)$ & $2(66.7)$ & 4.536 & 0.104 \\
\hline
\end{tabular}

Notes: $P$-value represents a comparison between patients with grade $2 \mathrm{~b}$ and grade I corrosive esophageal injury. $* P<0.05 ; * * P<0.01$. 
oxidative stress and reactive oxygen species in paraquatinduced neurotoxicity that seemed to be mediated by both mitochondrial and endoplasmic reticulum stress pathways. ${ }^{29}$ Several molecular mechanisms including redox cycling, mitochondrial electron transport chain inhibition, and activation of nicotinamide adenine dinucleotide phosphate oxidases have been proposed as potential sources for reactive oxygen species formation, particularly for the accumulation of superoxide anion. However, the exact molecular targets being regulated by oxidative stress and reactive oxygen species in response to paraquat remain elusive. ${ }^{29}$ Basic glyphosatesurfactant-induced neurotoxicity research is still lacking.

The mortality rates for glyphosate-surfactant and paraquat poisoning were $8.3 \%$ and $13.0 \%$, respectively $(P=0.601)$. Theoretically, glyphosate-surfactant cases should have lower mortality rates after ingestion than paraquat cases. Unlike paraquat, glyphosate-surfactant is claimed to be a very toxicologically and environmentally safe herbicide. ${ }^{30}$ Nevertheless, glyphosate-surfactant contains toxic substances in its commercial formula. Every glyphosate product is composed of three parts, ie, the parent acid, salt, proprietary components (surfactants, defoamers, and other compounds), and water. ${ }^{14}$ Notably, the proprietary components are listed as inert ingredients on product labels, and manufacturers are not required to provide information about these components. Following a standard detoxification protocol, the overall in-hospital mortality rate after paraquat ingestion was found to be $54 \%{ }^{1}$ Therefore, the lack of significant mortality in paraquat cases may be explained by the limited recruitment of patients into this study due to lack of endoscopic data.

It has been suggested that the magnitude of corrosive esophageal injury (a local complication) might be associated with systemic complications regardless of herbicide type (Table 5). As mentioned, our preliminary data ${ }^{6}$ revealed a potential relationship between degree of hypoxia, mortality, and degree of esophageal injury after ingestion of paraquat. Similarly, the study by Chang et $\mathrm{al}^{20}$ reported that white blood cell count, amount of glyphosate-surfactant, length of hospital stay, and occurrence of serious complications were markedly increased in the group that had grade 2 esophageal injuries than in the other groups. Therefore, the analysis suggested that severity of esophageal injury might be predictive of systemic complications. ${ }^{20}$

In conclusion, paraquat and glyphosate-surfactant are mild caustic agents that produce only grade 1, 2a, and $2 \mathrm{~b}$ esophageal injuries. Our data revealed a potential relationship between degree of esophageal injury and systemic complications. Nevertheless, the small patient population, small number of endoscopies, lack of information on blood glyphosate and surfactant concentration, and a relatively short follow-up period limit the certainty of our conclusions. As such, further studies are warranted.

\section{Acknowledgment}

Tzung-Hai Yen was funded by research grants from the Chang Gung Memorial Hospital (CMRP G3C0771) and National Science Council of Taiwan (NSC 102-2314-B-182-044-).

\section{Disclosure}

The authors report no conflicts of interest in this work.

\section{References}

1. Weng $\mathrm{CH}, \mathrm{Hu} \mathrm{CC}$, Lin JL, et al. Sequential organ failure assessment score can predict mortality in patients with paraquat intoxication. PLoS One. 2012;7(12):e51743.

2. Vale JA, Meredith TJ, Buckley BM. Paraquat poisoning: clinical features and immediate general management. Hum Toxicol. 1987;6(1):41-47.

3. Talbot AR, Barnes MR. Radiotherapy for the treatment of pulmonary complications of paraquat poisoning. Hum Toxicol. 1988;7(4): 325-332.

4. Hampson EC, Pond SM. Failure of haemoperfusion and haemodialysis to prevent death in paraquat poisoning. A retrospective review of 42 patients. Med Toxicol Adverse Drug Exp. 1988;3(1):64-71.

5. Lin JL, Lin-Tan DT, Chen KH, et al. Improved survival in severe paraquat poisoning with repeated pulse therapy of cyclophosphamide and steroids. Intensive Care Med. 2011;37(6):1006-1013.

6. Yen TH, Lin JL, Lin-Tan DT, Hsu CW, Weng CH, Chen YH. Spectrum of corrosive esophageal injury after intentional Paraquat ingestion. Am J Emerg Med. 2010;28(6):728-733.

7. Tsai TY, Weng CH, Lin JL, Yen TH. Suicide victim of paraquat poisoning make suitable corneal donor. Hum Exp Toxicol. 2011;30(1):71-73.

8. Hsu CW, Lin JL, Lin-Tan DT, et al. Early hemoperfusion may improve survival of severely paraquat-poisoned patients. PLoS One. 2012;7(10):e48397.

9. Yang CJ, Lin JL, Lin-Tan DT, et al. Spectrum of toxic hepatitis following intentional paraquat ingestion: analysis of 187 cases. Liver Int. 2012;32(9):1400-1406.

10. Hsieh YW, Lin JL, Lee SY, et al. Paraquat poisoning in pediatric patients. Pediatr Emerg Care. 2013;29(4):487-491.

11. Lin JL, Liu L, Leu ML. Recovery of respiratory function in survivors with paraquat intoxication. Arch Environ Health. 1995;50(6):432-439.

12. Serra A, Domingos F, Prata MM. Paraquat intoxication. Acta Med Port. 2003;16(1):25-32. Portuguese.

13. Lee HL, Kan CD, Tsai CL, Liou MJ, Guo HR. Comparative effects of the formulation of glyphosate-surfactant herbicides on hemodynamics in swine. Clin Toxicol. 2009;47(7):651-658.

14. Bradberry SM, Proudfoot AT, Vale JA. Glyphosate poisoning. Toxicol Rev. 2004;23(3):159-167.

15. Ackrill P, Hasleton PS, Ralston AJ. Oesophageal perforation due to paraquat. BMJ. 1978;1(6122):1252-1253.

16. Valiante F, Farinati F, Dal Santo P, Germana B, Di Mario F, Naccarato R. Upper gastrointestinal injury caused by diquat. Gastrointest Endosc. 1992;38(2):204.

17. Tanen DA, Curry SC, Laney RF. Renal failure and corrosive airway and gastrointestinal injury after ingestion of diluted diquat solution. Ann Emerg Med. 1999;34(4 Pt 1):542-545.

18. Singh S, Bambery P, Chaudhry D, Makharia G, Kakkar N, Singh D. Fatal paraquat poisoning: report of two cases. JAssoc Physicians India. 1999;47(8):831-832.

19. Mui PC. Endoscopic evaluation of paraquat-induced upper gastrointestinal injury. Gastrointest Endosc. 1993;39(1):105-106. 
20. Chang CY, Peng YC, Hung DZ, Hu WH, Yang DY, Lin TJ. Clinical impact of upper gastrointestinal tract injuries in glyphosate-surfactant oral intoxication. Hum Exp Toxicol. 1999;18(8):475-478.

21. Talbot AR, Shiaw MH, Huang JS, et al. Acute poisoning with a glyphosate-surfactant herbicide ('Roundup'): a review of 93 cases. Hum Exp Toxicol. 1991;10(1):1-8.

22. Tominack RL, Yang GY, Tsai WJ, Chung HM, Deng JF. Taiwan National Poison Center survey of glyphosate-surfactant herbicide ingestions. J Toxicol Clin Toxicol. 1991;29(1):91-109.

23. Sribanditmongkol P, Jutavijittum P, Pongraveevongsa P, Wunnapuk K, Durongkadech P. Pathological and toxicological findings in glyphosatesurfactant herbicide fatality: a case report. Am J Forensic Med Pathol. 2012;33(3):234-237.

24. Deo SP, Shetty P. Accidental chemical burns of oral mucosa by herbicide. JNMA J Nepal Med Assoc. 2012;52(185):40-42.

25. Ashford NA, Castleman B, Frank AL, et al. The International Commission on Occupational Health $(\mathrm{ICOH})$ and its influence on international organizations. Int J Occup Environ Health. 2002;8(2):156-162.
26. Liu SH, Lin JL, Weng CH, et al. Heart rate-corrected QT interval helps predict mortality after intentional organophosphate poisoning. PLoS One. 2012;7(5):e36576.

27. Zargar SA, Kochhar R, Nagi B, Mehta S, Mehta SK. Ingestion of corrosive acids. Spectrum of injury to upper gastrointestinal tract and natural history. Gastroenterology. 1989;97(3):702-707.

28. Moon JM, Chun BJ. Predicting acute complicated glyphosate intoxication in the emergency department. Clin Toxicol. 2010;48(7):718-724.

29. Franco R, Li S, Rodriguez-Rocha H, Burns M, Panayiotidis MI. Molecular mechanisms of pesticide-induced neurotoxicity: relevance to Parkinson's disease. Chem Biol Interact. 2010;188(2):289-300.

30. Duke SO, Powles SB. Glyphosate: a once-in-a-century herbicide. Pest Manag Sci. 2008;64(4):319-325.
International Journal of General Medicine

\section{Publish your work in this journal}

The International Journal of General Medicine is an international, peer-reviewed open-access journal that focuses on general and internal medicine, pathogenesis, epidemiology, diagnosis, monitoring and treatment protocols. The journal is characterized by the rapid reporting of reviews, original research and clinical studies across all disease areas.

\section{Dovepress}

A key focus is the elucidation of disease processes and management protocols resulting in improved outcomes for the patient.The manuscript management system is completely online and includes a very quick and fair peer-review system. Visit http://www.dovepress.com/ testimonials.php to read real quotes from published authors.

Submit your manuscript here: http://www.dovepress.com/international-journal-of-general-medicine-journal 